OPEN ACCESS

Edited by:

Maria Konsta-Gdoutos, University of Texas at Arlington,

United States

Reviewed by:

Ali Behnood,

Purdue University, United States

Pan Wang,

Qingdao University of Technology,

China

*Correspondence:

$\mathrm{NaCui}$

cea_cuin@ujn.edu.cn

Shuyuan Zhao

angel.zsy@hit.edu.cn

Ning Xie

xieningmt@163.com

Specialty section:

This article was submitted to

Structural Materials,

a section of the journal

Frontiers in Materials

Received: 15 April 2021

Accepted: 04 June 2021

Published: 18 June 2021

Citation:

Zhao Y, Cui N, Zhao S, Zhu Y, Hou P. Feng $L$ and Xie N (2021) Aggressive Environment Resistance of Concrete

Products Modified With Nano Alumina and Nano Silica.

Front. Mater. 8:695624.

doi: 10.3389/fmats.2021.695624

\section{Aggressive Environment Resistance of Concrete Products Modified With Nano Alumina and Nano Silica}

\author{
Yao Zhao ${ }^{1}, \mathrm{Na} \mathrm{Cui}^{1 *}$, Shuyuan $\mathrm{Zhao}^{2 *}$, Yunzhe $\mathrm{Zhu}^{2}$, Pengkun Hou ${ }^{1}$, Lichao Feng $^{3}$ and \\ Ning $\mathrm{Xie}^{1,2 *}$
}

${ }^{1}$ Shandong Provincial Key Laboratory of Preparation and Measurement of Building Materials and School of Civil Engineering and Architecture, University of Jinan, Jinan, China, ${ }^{2}$ Center for Composite Materials, Harbin Institute of Technology, Harbin, China, ${ }^{3}$ Jiangsu Marine Resources Development Research Institute and School of Mechanical Engineering, Jiangsu Ocean University, Lianyungang, China

The service life of concrete products with exposure to an aggressive environment has raised great concerns in the past decades. Nanomaterials have been used as a promising approach to improve the environmental resistance of concrete products when exposed to synergistic attacks. The impacts of $\mathrm{CaCl}_{2}$ on nano-modified concrete, especially along with freeze/thaw (F/T) and wet/dry (W/D) cycles, were barely discussed. In this study, the impacts of $\mathrm{CaCl}_{2}$ along with $\mathrm{F} / \mathrm{T}$ and W/D cycles on the nano $\mathrm{SiO}_{2}$ and $\mathrm{Al}_{2} \mathrm{O}_{3}$ modified concrete were investigated. The mass loss, flexural strength, compressive strength, and relative dynamic modulus of elasticity were tested to evaluate the durability of concrete products. The testing results indicate that the addition of nanoparticles has a distinctive effect on the environment resistance enhancement of concrete samples. The microstructure analysis demonstrates that with the addition of nanoparticles, highdensity hydration products were formed, which is beneficial to the properties enhancement of concrete products. This study not only provides an approach to realize the nano modification on the durability of concrete products but also helps to design and fabricate environmentally resistant concrete products when exposed to a synergistic aggressive environment.

Keywords: chemical resistance, concrete products, nano modification, microstructure analysis, deleterious mechanism

\section{INTRODUCTION}

In cold regions, chemicals have been widely utilized as deicers to control the ice and snow on the road. Despite using deicing chemicals can significantly improve transportation efficiency and mitigate the damage from traffic accidents in the winter season, the side effect of using deicing chemicals is also inevitable. Currently, the widely used deicing chemicals include $\mathrm{NaCl}$, $\mathrm{MgCl}_{2}, \mathrm{CaCl}_{2}$, and even $\mathrm{CaAc}_{2}$. It has been widely accepted that the concrete products will severely deteriorate when exposed to aggressive environments, such as freeze/thaw $(\mathrm{F} / \mathrm{T})$ and wet/dry (W/D) cycling, especially along with attacks from the deicers. Although previous studies have pointed out that the failure of concrete products with exposure to an aggressive environment can be attributed to physical scaling and chemical reactions between the aggressive agents and the C-S-H binder phase, which synergistically result in the deterioration of the concrete products (Farnam et al., 2015; Qiao et al., 2018a), the 
agreement of the chemical deteriorate mechanisms and the microstructure evolution process was yet achieved.

Numerous studies have reported that the deleterious process of concrete products is complicated and the damage mechanism is synergistic (Peterson et al., 2013; Xie et al., 2019). In a laboratory study, the deleterious process of concrete products with exposure to inorganic chemical solutions along with freeze/ thaw and wet/dry cycles had been investigated. It was reported that all concrete products exhibited various mass and strength variations, and the microstructure of the cement hydration products was distinctively changed after a long term of soaking in the chemical solutions (Shi et al., 2013). In addition to the inorganic chemical solutions, the impact of the organic chemical solutions on the durability of concrete products has been studied (Xie et al., 2017). It was pointed out that the organic chemicals posed a negative impact on the durability of concrete products, especially for the concrete products prepared with reactive aggregates, which lead to the aggregate silicate reaction. The microstructure analysis demonstrated that the distress of the concrete was attributed to the leaching of the $\mathrm{Ca}$ from the C-S-H binder phase. Although the mechanical properties and durability of concrete products can be enhanced by many approaches such as using supplementary cementitious materials, fiber reinforcement, or water/binder ratio reduction, the side effects of these methods are also apparent, including high internal stress, thermal cracks, adhesion and corrosion problems of reinforced fibers. As a result, it is compelling to explore appropriate materials or technologies to mitigate the side effects of traditional modification methods.

In the past decades, it has been widely accepted that the hydration products of cementitious materials are composed of nanoscale phases (Xu and Viehland, 1996; Allen et al., 2007a; Allen and Thomas, 2007b). As a result, many studies have tried using nanomaterials to manipulate the microstructures of these nano-sized phases to enhance the durability of concrete products (Monteiro et al., 2009; Morsy et al., 2012; Lim and Mondal, 2014; Lu et al., 2015). The most widely used nanomaterials were titanium dioxide $\left(\mathrm{TiO}_{2}\right)$ (Feng et al., 2013; Zhang et al., 2015), silica $\left(\mathrm{SiO}_{2}\right)$ (Hou et al., 2013; Shiho et al., 2013; Singh et al., 2013), alumina $\left(\mathrm{Al}_{2} \mathrm{O}_{3}\right)$ (Nazari et al., 2010), iron oxide $\left(\mathrm{Fe}_{2} \mathrm{O}_{3}\right)$ (Li et al., 2004; Heikal, 2016), nano clay (Hakamy and Shaikh, 2014; Fan et al., 2015), and carbon nanomaterials (Morsy et al., 2011; Lv et al., 2013; Pan et al., 2015; Erdem et al., 2017; Luo et al., 2017; Zhou and Xie, 2020). It was claimed that with the addition of $\mathrm{TiO}_{2}, \mathrm{SiO}_{2}$, and $\mathrm{Fe}_{2} \mathrm{O}_{3}$ nanoparticles, the mechanical properties and wear resistance of the concrete products have been enhanced, and nano $\mathrm{TiO}_{2}$ had a higher modification effect than the nano $\mathrm{SiO}_{2}$ ( $\mathrm{Li}$ et al., 2004; Li et al., 2006). Apart from nano $\mathrm{TiO}_{2}$ particles, the effects of nano $\mathrm{Al}_{2} \mathrm{O}_{3}$ particles on the mechanical properties have been investigated. It was found that the 7 days compressive strength of concrete samples has enhanced by $30 \%$ and the 28 days elastic modulus has increased $143 \%$ with the addition of $5 \mathrm{wt} \% \mathrm{Al}_{2} \mathrm{O}_{3}$ nanoparticles ( $\mathrm{Li}$ et al., 2006).

In addition to the mechanical properties, the environmental resistance of concrete products can also be considerably enhanced with the addition of nanoparticles (Lu, 2013; Shah, 2013).
Behfarnia investigated the freeze/thaw resistance of the concrete materials modified by nano-silica and nano alumina. The results indicated that, after 300 freeze/thaw cycles in water, the strength of the concrete samples with or without nano modification decreased 16 and 100\%, respectively, (Behfarnia and Salemi, 2013). A similar statement was claimed that the addition of nano $\mathrm{SiO}_{2}$ and nano $\mathrm{Al}_{2} \mathrm{O}_{3}$ has positive effects on the freeze/thaw resistance of concrete. With the addition of $5 \mathrm{wt} \%$ nano $\mathrm{SiO}_{2}$ or nano $\mathrm{Al}_{2} \mathrm{O}_{3}$, the freeze/thaw resistance of the concrete samples enhanced by over $80 \%$ comparing with the control samples (Salemi and Behfarnia, 2013).

Previous studies have stated that the modification mechanisms of the nanomaterials on the concrete materials can be attributed to the following reasons: 1 ) act as nano-sized fillers to decrease the nano-sized pores in the hydration products of the cementitious materials; 2) serve as the "nucleus" to align the hydration process and tune the microstructure evolution of the cementitious hydration products; 3) promote the forming of high-density $\mathrm{C}-\mathrm{S}-\mathrm{H}$ phase. Despite these mechanisms have been stated for many years, the modification mechanism of diverse nanomaterials on the properties of concrete materials remains unclear.

To elucidate the modification mechanism of the nanoparticles on the cement concrete, microstructure analysis is a promising method that can tell the impacts of nanoparticles on the microstructure evolution process. Scanning electron microscopy has been widely used to characterize the microstructure of concrete or cementitious materials with or without nano modification (Qing et al., 2007; Kong et al., 2012; Meng et al., 2012; Kong et al., 2013). According to the fracture surface morphology analysis, it can be found that the microstructures of Portland cement paste modified with nanomaterials are composed of $\mathrm{Ca}(\mathrm{OH})_{2}$, amorphous C-S-H phase, and pores (Li et al., 2004). Previous studies have assumed that the nanoparticles will act as nuclei to help growing new types of nanostructural hydration products, such as needle-shaped (or wireshaped) hydration products. The EDS results showed that the needle-shaped hydration products were composed of $\mathrm{Al}, \mathrm{Ca}$, and $\mathrm{Si}$ with a $\mathrm{Ca} / \mathrm{Si}$ ratio of $5: 1$ and $\mathrm{Al} / \mathrm{Si}$ ratio of 3:5. Meanwhile, the adjacent area featured the $\mathrm{Ca} / \mathrm{Si}$ and $\mathrm{Al} / \mathrm{Si}$ ratio of $2: 1$ and $1: 6$, respectively, (Feng, 2012). Another study has also observed these needle-shaped hydration products and claimed them as ettringite. Based on the EDS analysis of the needle-shaped phases, it can be found that the main chemical composition of these phases was $\mathrm{Ca}$, $\mathrm{Al}$, and $\mathrm{O}$, and a large amount of $\mathrm{Si}$, little $\mathrm{S}$ was detected. Therefore, it can be deduced that the needle-shaped phase is more complicated than the ettringite.

Although the benefits of the nano modification are observable, the potential strengthening mechanisms are yet crystal clear. A few studies have argued that the benefits of the nano modification are questionable from the perspective of the nanoparticle types, especially with the addition of $\mathrm{Al}_{2} \mathrm{O}_{3}$ nanoparticles. It was claimed that the nano $\mathrm{Al}_{2} \mathrm{O}_{3}$ has negative effects on the durability enhancement of concrete products (Leòn et al., 2014). Furthermore, to the best of our knowledge, limited studies were implemented to investigate the damage mechanism of nano-modified concrete with exposure to freeze/thaw cycling along with the attacks of $\mathrm{CaCl}_{2}$. As a 
TABLE 1 | Mix design of the nano-modified concrete.

\begin{tabular}{|c|c|c|c|c|c|}
\hline $\begin{array}{l}\text { Water to } \\
\text { cement ratio }\end{array}$ & Cement $\left(\mathrm{kg} / \mathrm{m}^{3}\right)$ & Water $\left(\mathbf{k g} / \mathrm{m}^{3}\right)$ & $\begin{array}{c}\text { Fine aggregate } \\
\qquad\left(\mathrm{kg} / \mathrm{m}^{3}\right)\end{array}$ & $\begin{array}{c}\text { Coarse aggregate } \\
\left(\mathrm{kg} / \mathrm{m}^{3}\right)\end{array}$ & $\begin{array}{c}\text { Water reducer } \\
(\%)\end{array}$ \\
\hline 0.50 & 376 & 188 & 679 & 1,157 & 0.5 \\
\hline
\end{tabular}

result, it is critical to find out the potential modification mechanism of diverse nanomaterials on the concrete products with exposure to the freeze/thaw and wet/dry cycles along with $\mathrm{CaCl}_{2}$ attacks.

\section{EXPERIMENTAL METHODS AND MATERIALS}

Ordinary Portland cement (P.O 42.5), natural sand, and basalt rocks were used as raw materials. Commercially available $\mathrm{SiO}_{2}$ and $\mathrm{Al}_{2} \mathrm{O}_{3}$ nanoparticles (provided by Hefei Liangziyuan Co.) were used as the modifiers. The purity of the nanomaterials was higher than $99.0 \%$, and the average size and the specific surface area were about $30 \mathrm{~nm}$ and $80 \mathrm{~m}^{2} / \mathrm{g}$, respectively.

The dosages of the nano modifiers were $0,0.05,0.1,0.5$, and $1.0 \%$ by the weight of cement. The water/cement ratio $(\mathrm{w} / \mathrm{c})$ was 0.5 , and the mix proportion of the nano-modified concrete is listed in Table 1. To realize a dispersion condition of the nanoparticles, the naphthalene water reducer (UNF-5), with a content of $0.5 \mathrm{wt} \%$ of cement, was mixed in water via magnetic stirring with a mixing speed of $1,500 \mathrm{rpm}$ for $5 \mathrm{~min}$. Subsequently, the nano modifiers were added to the mixture and followed by sonication $(200 \mathrm{w}$ and $40 \mathrm{~Hz}$ ) for $10 \mathrm{~min}$. After sufficient mixing of the raw materials, the fresh concrete mixture was cast into steel molds with a size of $100 \mathrm{~mm}^{3} \times 100 \mathrm{~mm}^{3} \times$ $400 \mathrm{~mm}^{3}$. The specimens were de-molded after $24 \mathrm{~h}$ and cured in a moist room with relative humidity $(\mathrm{RH})$ of $95 \%$ at $25^{\circ} \mathrm{C}$ for another 27 days. Once fully cured, the concrete specimens were air-dried for $24 \mathrm{~h}$ at $25^{\circ} \mathrm{C}$ at $\mathrm{RH} 45-55 \%$ and weighed before testing. The slump testing was based on the ASTM C143.

The impacts of the chemical attacks on the durability of nanomodified concrete products were evaluated by comparing the performance of concrete samples before and after freeze/thaw and wet/dry cycles in a diluted $\mathrm{CaCl}_{2}$ solution with a concentration of $3 \mathrm{wt} \%$. An accelerated manner of 3, 7, and 15 freeze/thaw and wet/dry cycles were used as the testing process. In each cycle, freezing the concrete samples in the diluted $\mathrm{CaCl} 2$ solution at $-25^{\circ} \mathrm{C}$ for $48 \mathrm{~h}$ and followed by thawing for $24 \mathrm{~h}$ and air-dried for another $12 \mathrm{~h}$ at room temperature $\left(25^{\circ} \mathrm{C}, \mathrm{RH} 50 \pm\right.$ $5 \%)$. The freezing and thawing rates were approximately 0.05 and $0.01^{\circ} \mathrm{C} /$ minute, respectively. After freeze/thaw and wet/dry cycles, the samples were washed and the scaled-off materials on the surface were removed by hands. Finally, the weights of the samples were recorded and the properties were tested accordingly. The compressive and flexural strengths of the concrete samples were determined using ASTM C39 and ASTM C496, respectively. The relative dynamic modulus of elasticity was obtained by testing the time of the supersonic wave passing through the concrete samples before and after freeze/thaw and wet/dry cycles. The testing period was $0.4 \mu \mathrm{s}$ with a voltage of $500 \mathrm{~V}$. The relative dynamic modulus of elasticity was calculated based on the following equation:

$$
R_{\mathrm{n}}=\frac{t_{0}^{2}}{t_{\mathrm{n}}^{2}} \times 100
$$

where $R_{n}$ is the relative dynamic modulus of the concrete after $n$ times of freeze/thaw and wet/dry cycles, $t_{0}$ is the time that the supersonic wave passing through the concrete samples before freeze/thaw and wet/dry, and $t_{n}$ is the time that the supersonic wave passing through the concrete samples after $n$ times of freeze/ thaw and wet/dry cycles.

The electric flux was tested according to GB/T 50082-2009. In this process, 28 days samples with a size of $150 \mathrm{~mm} \times 150 \mathrm{~mm} \times$ $150 \mathrm{~mm} \times 51 \mathrm{~mm}$. After properly connected, a constant $60 \mathrm{~V}$ direct current power was applied to the testing device, and the current values were recorded every $15 \mathrm{~min}$. The final results were the average value of three samples.

The non-evaporable water content was obtained by calculating the mass change of the hardened paste before and after the calcination process. First, the samples were heated in air for $1 \mathrm{~h}$ at $85^{\circ} \mathrm{C}$ and then ground into powders. After an $80 \mu \mathrm{m}$ sieving, the fine powders were dried at $105^{\circ} \mathrm{C}$ to reach a constant mass value and followed by calcination at $950^{\circ} \mathrm{C}$ for $1 \mathrm{~h}$. The nonevaporable water can be calculated according to the following equation:

$$
w_{\mathrm{C}}=\frac{m_{1}-m_{2}}{m_{2}} \times\left(100-w_{\mathrm{LOI}}\right) / w_{\mathrm{LOI}}
$$

where $w_{c}$ is the content of the non-evaporable water, $m_{1}$ and $m_{2}$ are the mass of the cement powder before and after calcination, and $w_{L O I}$ is the loss of ignition of the cement.

The heat of hydration was measured by TAM Air isothermal calorimeter with the inner mixing mode at $25^{\circ} \mathrm{C}$. The temperature range of the thermogravimetric analysis (TA-SDT-Q600) was $30-800^{\circ} \mathrm{C}$. A scanning electron microscope (FEI-Quanta 200F) coupled with energy-dispersive X-ray spectroscopy (EDS) analyzer was used to analyze the fracture surface morphologies of concrete samples before and after the freeze/thaw and wet/dry cycles in the $\mathrm{CaCl}_{2}$ solution. The EDS results were obtained from the selected zone corresponding to the SEM morphology images. A typical $15-20 \mathrm{kV}$ accelerating voltage was used with a scan time over $60 \mathrm{~s}$ per sampling area.

\section{RESULTS AND DISCUSSION}

Figure 1 gives the slump of fresh concrete samples as a function of the content of $\mathrm{Al}_{2} \mathrm{O}_{3}$ nanoparticles via using nano $\mathrm{SiO}_{2}$ as reference. As can be seen from this figure, the slump of the nano- 


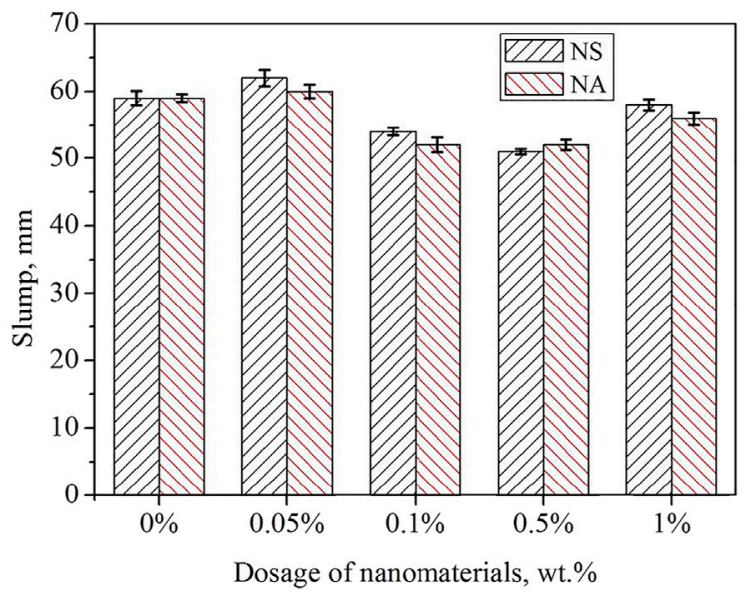

FIGURE 1 | Slum of concrete as a function of the dosage of nanoparticles.

modified concrete was not distinctively reduced with increasing the dosage of nanoparticles when the dosage was lower than $1 \mathrm{wt}$ $\%$. The slumps of the nano $\mathrm{SiO}_{2}$ and nano $\mathrm{Al}_{2} \mathrm{O}_{3}$ modified concrete is lower than $65 \mathrm{~mm}$, which is acceptable for field applications. Comparing with previous studies, the appropriate workability was originated from the low dosage of the nanomaterials. As demonstrated from this figure, the dosage of the nanomaterials was in a range of 0.05 to $1 \mathrm{wt} \%$, which is lower than previous studies. If the contents of the nanomaterials increased from 1 to $5 \%$, the workability of the concrete will be significantly decreased. It has been demonstrated that the high dosage addition of nanomaterials will significantly decrease the workability of the concrete (Nazari et al., 2010; Li et al., 2006). A few studies have even claimed that, if using the workability as the control parameter, the modification effect of nano $\mathrm{Al}_{2} \mathrm{O}_{3}$ was not distinctive (Berra et al., 2012). Therefore, it is a critical issue to realize the mechanical properties enhancement without sacrifice the workability of nano-modified concrete. Comparing with increasing the water/binder ratio or the dosage of water reducers, decreasing the content of nanoparticles is a costeffective method to prepare high property nano-modified concrete.

Figure 2 shows the mechanical properties of concrete samples as a function of the dosage of nano $\mathrm{SiO}_{2}$ and nano $\mathrm{Al}_{2} \mathrm{O}_{3}$ particles. As demonstrated in this figure, the mechanical properties, including the compressive strength and the flexural strength, have been slightly increased with the increasing content of nanoparticles. Although the enhancement effect is not that distinctive, the average compressive strength of the nanomodified samples increased about 15\% comparing with the control samples from 32.5 to $37.3 \mathrm{MPa}$ and $37.0 \mathrm{MPa}$, respectively, with $1.0 \mathrm{wt} \%$ addition of nano $\mathrm{SiO}_{2}$ and nano $\mathrm{Al}_{2} \mathrm{O}_{3}$. Similarly, the flexural strengths have also been slightly enhanced with the increasing content of the nanomaterials. Without the addition of nanomaterials, the flexural strength of the control sample was about $4.4 \mathrm{MPa}$, while with the addition of $1.0 \mathrm{wt} \%$ nano $\mathrm{SiO}_{2}$ and nano $\mathrm{Al}_{2} \mathrm{O}_{3}$ particles, the flexural

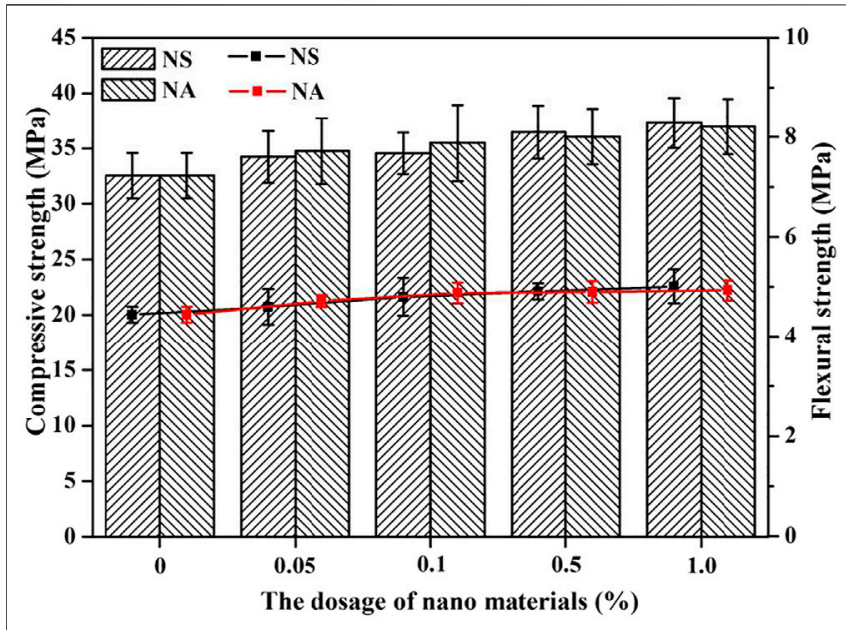

FIGURE 2 | Mechanical properties of concrete as a function of the dosage of nanoparticles.

strengths have increased 11 and 13\%, and reached 5.0 and 4.9 $\mathrm{MPa}$, respectively.

The chemical resistance of the nano $\mathrm{SiO}_{2}$ modified concrete samples with exposure to $\mathrm{F} / \mathrm{T}$ and $\mathrm{W} / \mathrm{D}$ cycles in a $3 \mathrm{wt} \% \mathrm{CaCl}_{2}$ solution is shown in Figure 3. As can be seen from Figure 3A), the mass loss of the concrete samples has considerably reduced with increasing contents of nano $\mathrm{SiO}_{2}$. Without the addition of nano $\mathrm{SiO}_{2}$, the mass loss was about $0.5,1.2$, and $2.8 \%$, while with the addition of $1 \mathrm{wt} \%$ nano $\mathrm{SiO}_{2}$, the mass loss decreased to 0.2 , 0.5 , and $1.7 \%$, after 3,7 , and 15 times of $\mathrm{F} / \mathrm{T}$ and $\mathrm{W} / \mathrm{D}$ cycles. Meanwhile, as demonstrated from Figures 3B-D), the nano modification effects on the relative dynamic modulus, the loss of compressive strength, and the loss of flexural strength are all observable. When the dosage of the nano $\mathrm{SiO}_{2}$ increased from 0 to $1 \mathrm{wt} \%$, the relative dynamic modulus increased from 95.4 to 97.4 , 87.3-92.6, and 72.0-78.1\% corresponding to 3, 7, and 15 times of F/T and W/D cycles. The loss of the compressive strength decreased from 3.5 to $0.9,8.3-3.8$, and $17.2-10.6 \%$ after 3,7 , and $15 \mathrm{~F} / \mathrm{T}$ and W/D cycles. The loss of the flexural strength decreased from 3.7 to $1.2,8.4-5.2$, and $20.5-16.1 \%$ after 3,7 , and $15 \mathrm{~F} / \mathrm{T}$ and $\mathrm{W} / \mathrm{D}$ cycles.

Similar to the nano $\mathrm{SiO}_{2}$, nano $\mathrm{Al}_{2} \mathrm{O}_{3}$ has been used as a modifier to strengthen the concrete products. It was claimed that the addition of nano $\mathrm{Al}_{2} \mathrm{O}_{3}$ is beneficial to the mechanical properties of concrete products; however, the impact of nano $\mathrm{Al}_{2} \mathrm{O}_{3}$ on the chemical resistance remains unclear. Figure 4 shows the chemical resistance performance of concrete samples as a function of nano $\mathrm{Al}_{2} \mathrm{O}_{3}$ contents. It can be found from the testing results, the mass loss of the nano $\mathrm{Al}_{2} \mathrm{O}_{3}$ modified concrete decreased to $0.2,0.6$, and $1.8 \%$, after 3,7 , and 15 times of $\mathrm{F} / \mathrm{T}$ and $\mathrm{W} / \mathrm{D}$ cycles in a $3 \mathrm{wt} \% \mathrm{CaCl}_{2}$ solution. With the contents of the nano $\mathrm{Al}_{2} \mathrm{O}_{3}$ increased from 0 to $1 \mathrm{wt} \%$, the relative dynamic modulus enhanced from 95.4 to $98.1 \%, 87.3-90.8 \%$, and $72.0-76.6 \%$ corresponding to 3,7 , and 15 times of F/T and $\mathrm{W} / \mathrm{D}$ cycles. The loss of the compressive strength decreased from 4.0 to $1.9,7.9-6.0$, and $17.5-14.5 \%$ after 3,7 , and $15 \mathrm{~F} / \mathrm{T}$ and W/D cycles. The loss of the flexural strength decreased from 


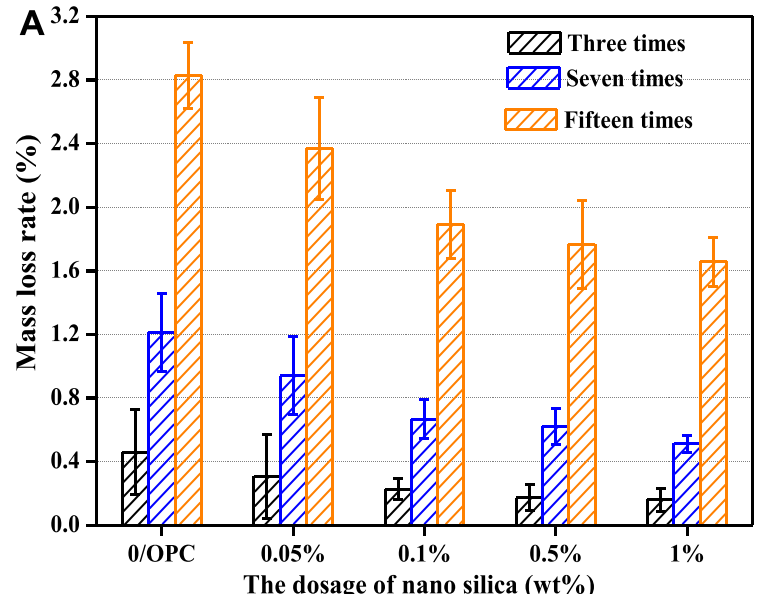

C

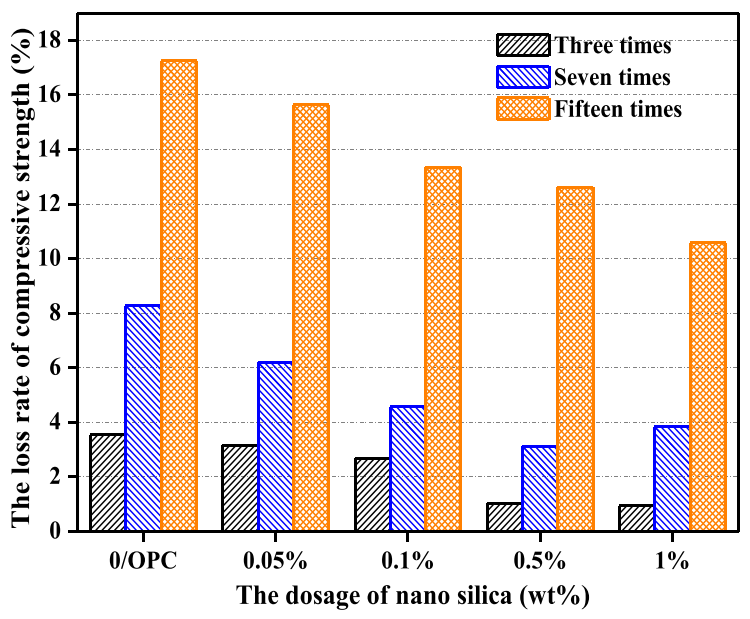

B

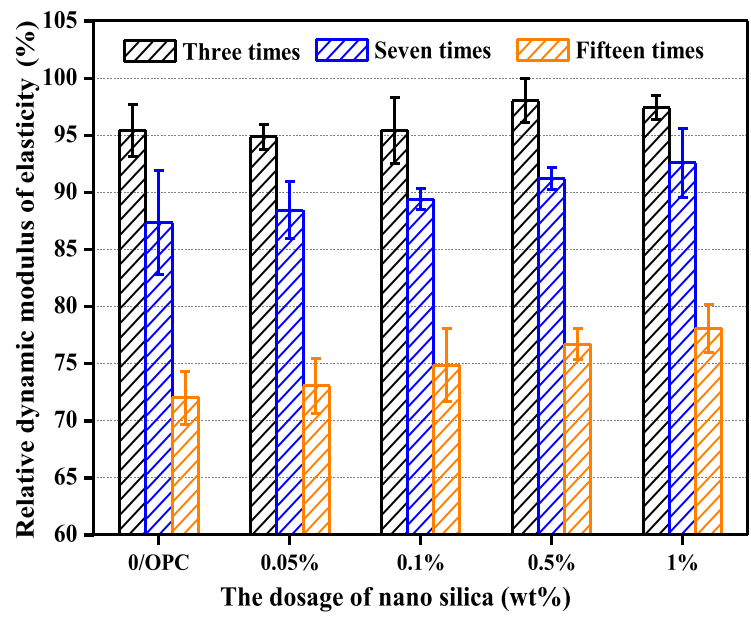

D

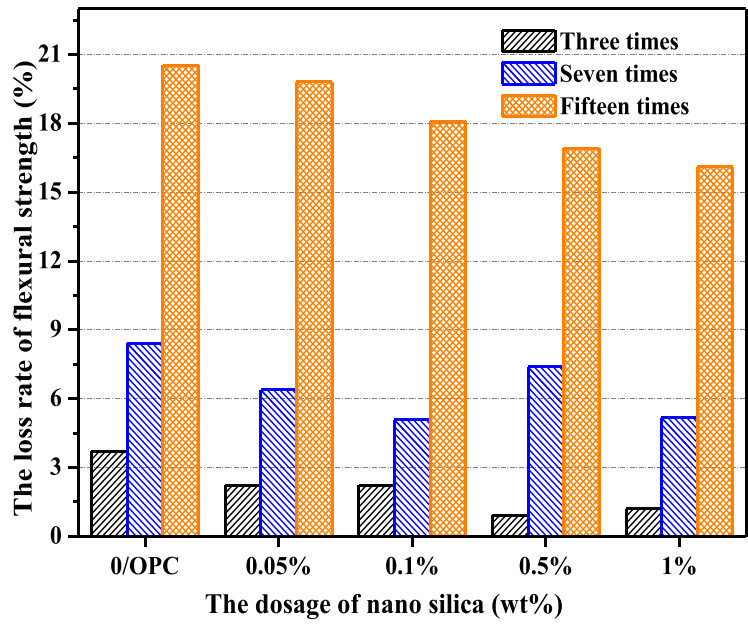

FIGURE 3 | (A) Mass loss rate, (B) Relative dynamic elastic modulus, (C) Loss rate of flexural strength, and (D) Loss rate of compressive strength of nano SiO 2 modified concrete samples experienced $\mathrm{F} / \mathrm{T}$ and $\mathrm{W} / \mathrm{D}$ cycles in a $3 \mathrm{wt} \%$ of $\mathrm{CaCl}_{2}$ solution.

3.4 to $2.1,10.1-7.8$, and $22.6-20.7 \%$ after 3,7 , and $15 \mathrm{~F} / \mathrm{T}$ and $\mathrm{W} / \mathrm{D}$ cycles.

Figure 5 shows the electric flux of concrete samples as a function of the contents of nanoparticles. As can be seen from this figure, the electric flux of concrete samples decreased with increasing the contents of nanoparticles, especially when the dosage of nano $\mathrm{SiO}_{2}$ reached $1.0 \mathrm{wt} \%$, the electric flux of the samples was reduced by about $30 \%$, from about 5,000 to 3,500 C. For the $\mathrm{Al}_{2} \mathrm{O}_{3}$ nano-modified concrete samples, the electric flux reduced from 5,000 to about $4100 \mathrm{C}$ when the dosage increased to $1.0 \mathrm{wt} \%$, suggesting that the permeability of the concrete samples has been reduced by the addition of nano $\mathrm{SiO}_{2}$ and nano $\mathrm{Al}_{2} \mathrm{O}_{3}$.

Figure 6 gives the isothermal calorimetry curves of the paste samples modified with nanoparticles. Figures 6A,B) demonstrate the total heat curves of the samples modified with nano $\mathrm{SiO}_{2}$ and nano $\mathrm{Al}_{2} \mathrm{O}_{3}$, respectively. As can be seen from this figure, with the addition of nanoparticles, the hydration process has been distinctively changed. Although there is a slight fluctuation with the dosage of $0.5 \mathrm{wt} \%$, the heat of hydration has considerably enhanced when the dosage of nanoparticles reached $1.0 \mathrm{wt} \%$. Figures 6 C,D) demonstrate the heat flow evaluation of the nano-modified cement paste samples corresponding to the same data group of Figures $6 \mathbf{A , B}$ ). In Figures $6 \mathrm{C}, \mathrm{D}$ ), the hydration heat of $\mathrm{C}_{3} \mathrm{~A}$ can be reflected by the first peak, and the hydration heat of $\mathrm{C}_{3} \mathrm{~S}$ can be detected through the second peak. As demonstrated in this figure, the distinctive increase of the hydration heat indicates the addition of the nanoparticles is beneficial to the early age hydration process of cement paste.

The effect of nanoparticles on the non-evaporable water contents is shown in Figure 7. It can be observed that the content of the non-evaporable water has considerably increased with the addition of the nanoparticles. This phenomenon demonstrates that the content of chemically bonded water in the hydration products can be increased because of the addition of the nanoparticles. Besides, the nano $\mathrm{SiO}_{2}$ shows a higher enhancement effect than the nano $\mathrm{Al}_{2} \mathrm{O}_{3}$. This mainly results from the pozzolanic activity of nano $\mathrm{SiO}_{2}$, which is beneficial to form more C-S-H phases $\left(\mathrm{xCaO} \bullet \mathrm{SiO}_{2} \bullet \mathrm{yH}_{2} \mathrm{O}, \mathrm{C}-\mathrm{S}-\mathrm{H}\right.$ gel). Meanwhile, although the 

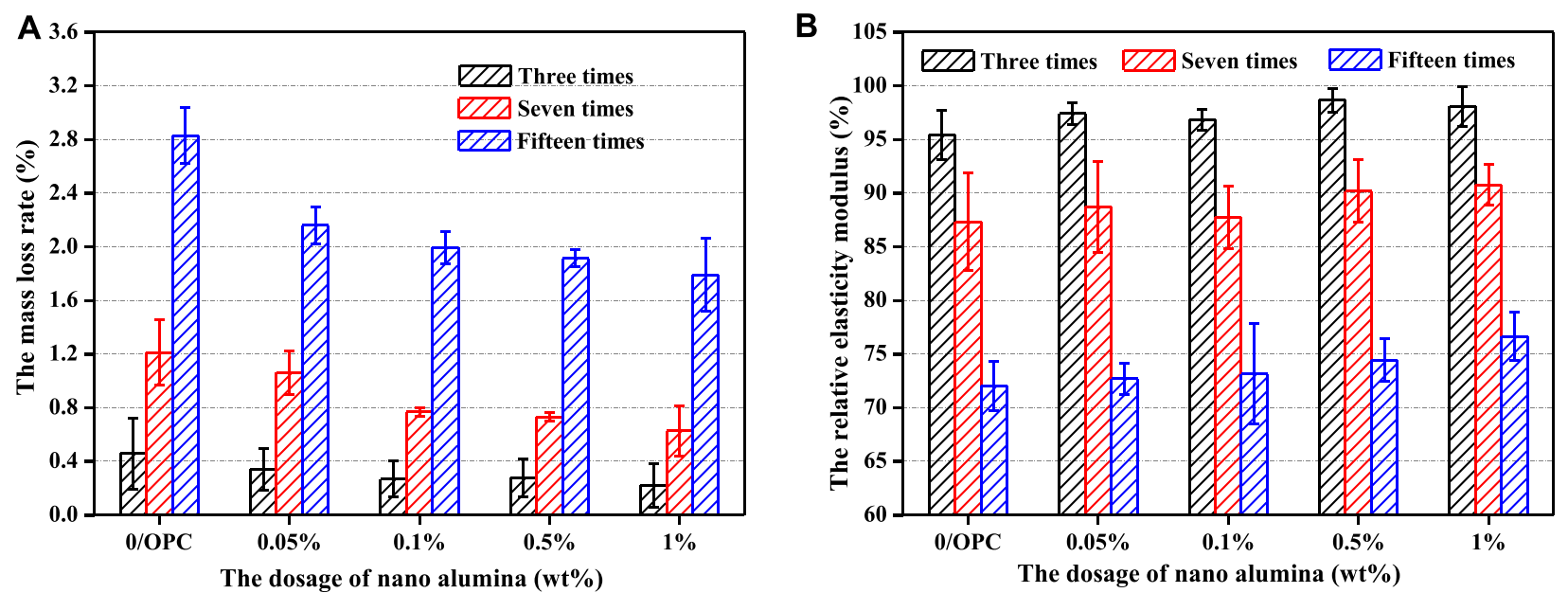

C
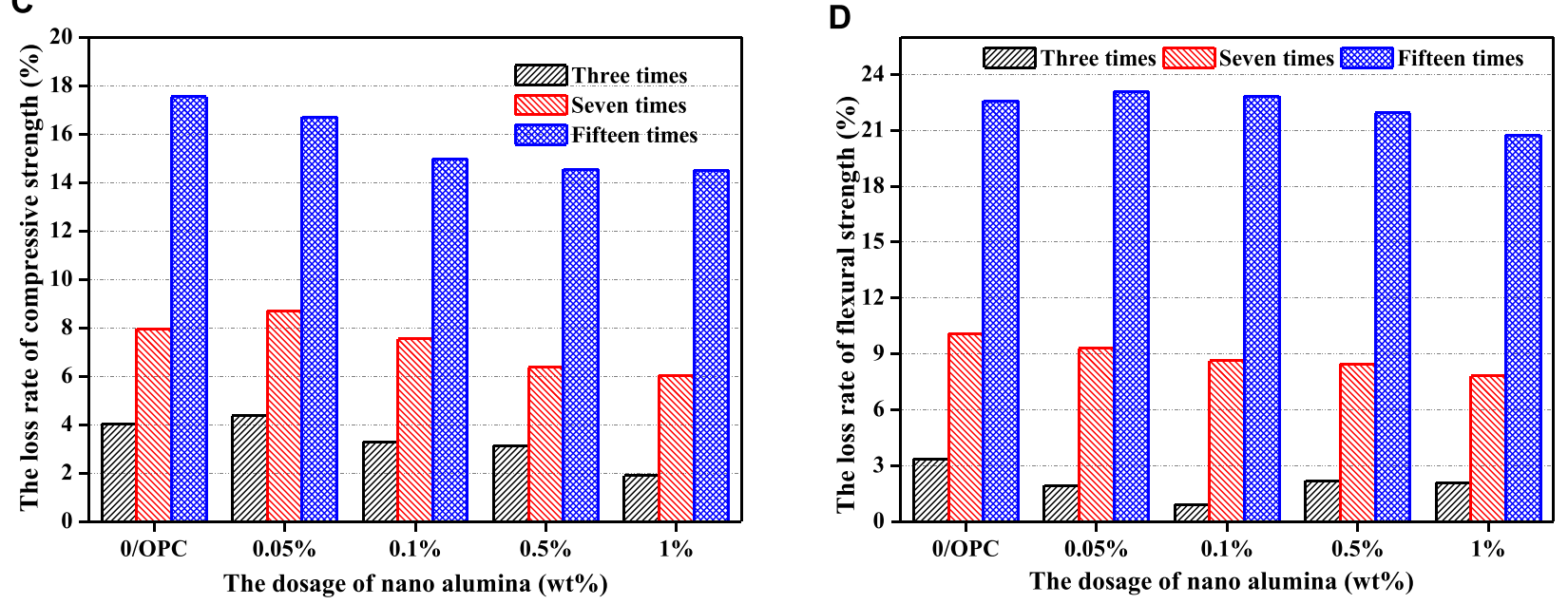

FIGURE 4 | (A) Mass loss rate, (B) Relative dynamic elastic modulus, (C) Loss rate of flexural strength, and (D) Loss rate of compressive strength of nano $\mathrm{Al}_{2} \mathrm{O}_{3}$ modified concrete samples experienced $\mathrm{F} / \mathrm{T}$ and $\mathrm{W} / \mathrm{D}$ cycles in a $3 \mathrm{wt} \%$ of $\mathrm{CaCl}_{2}$ solution.

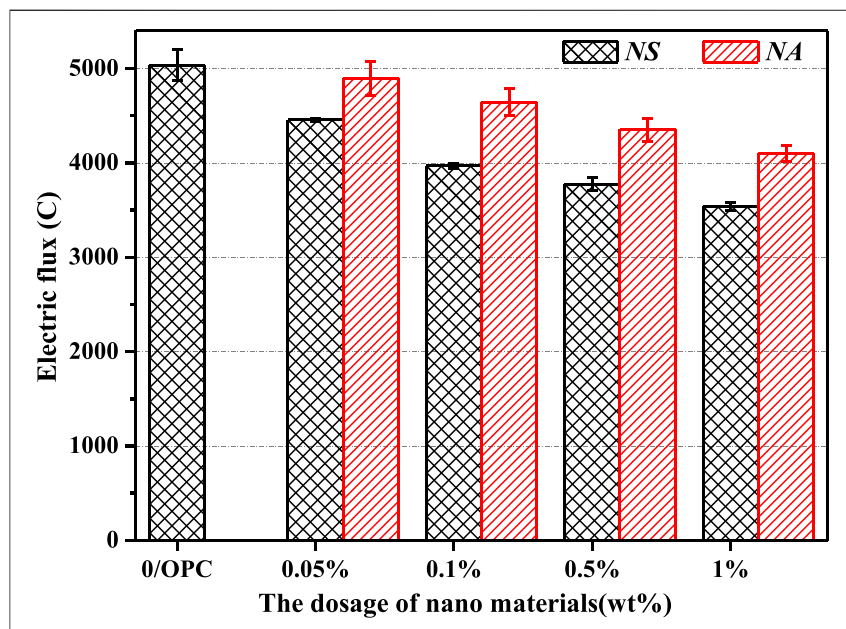

FIGURE 5|The effect of dosage on the electric flux of the nano-modified concrete. effect of nano $\mathrm{Al}_{2} \mathrm{O}_{3}$ is less than the nano $\mathrm{SiO}_{2}$, it still has a remarkable enhancement by comparing with the control samples. Previous studies have claimed that the amount of hydration products is proportional to the contents of the non-evaporable water. Therefore, it is reasonable to claim that nano $\mathrm{SiO}_{2}$ and $\mathrm{Al}_{2} \mathrm{O}_{3}$ are beneficial to optimize the phase structures.

Different from the physical $\mathrm{F} / \mathrm{T}$ scaling process, the deterioration of concrete with exposure to $F / T, W / D$, and chemical attacks is attributed to both physical and chemical mechanisms. The physical F/T damage mainly resulted from the hydraulic pressure, which is determined by the permeability of concrete materials, while the chemical deterioration is governed by the chemical reaction between the aggressive agents and the cementitious binder phases (Xie et al., 2017; Xie et al., 2019; Qiao et al., 2018a; Qiao et al., 2018b). According to the results from previous studies, it has been widely accepted that the $\mathrm{CaCl}_{2}$ will react with the $\mathrm{Ca}(\mathrm{OH})_{2}$ and form the volume expansive calcium oxychloride $\left(\mathrm{CaCl}_{2} \cdot 3 \mathrm{Ca}(\mathrm{OH})_{2} \cdot 12 \mathrm{H}_{2} \mathrm{O}\right)$, which increase the internal stress 


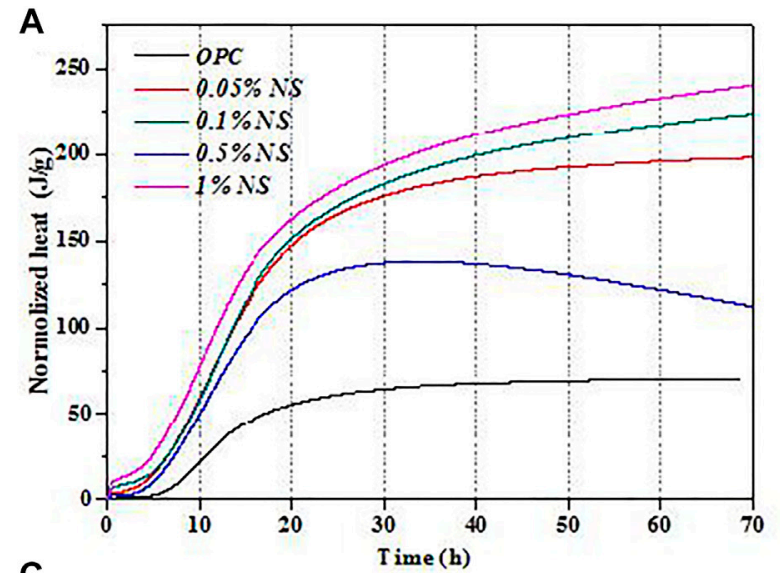

C

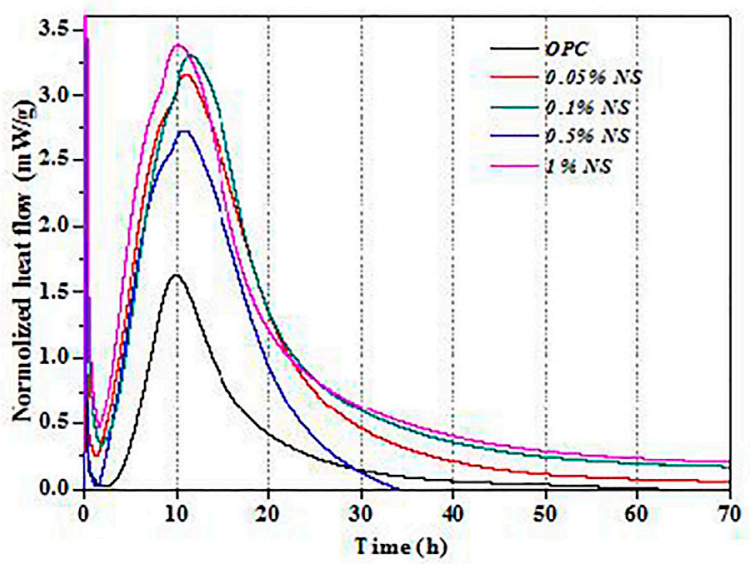

B

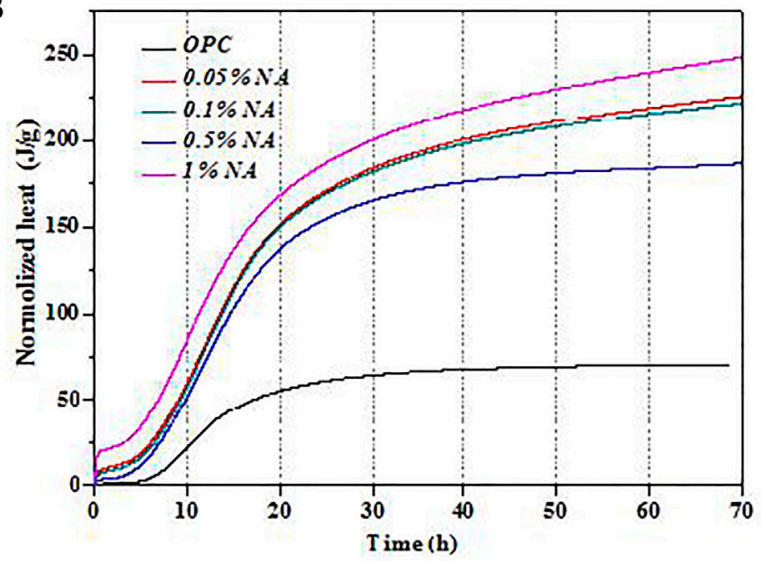

D

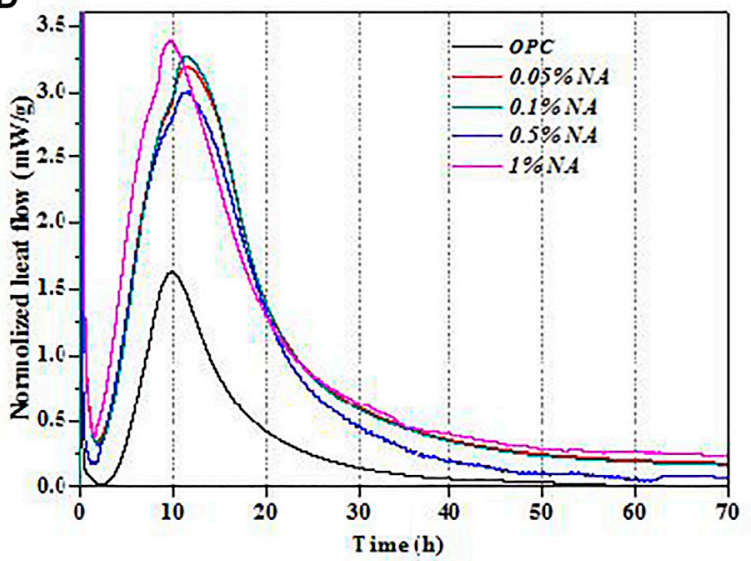

FIGURE 6 | The effect of nanomaterials on the hydration evolution of nano-modified cement paste. (A) Total heat curves of the samples modified with nano $\mathrm{SiO}_{2}$, (B) total heat curves of the samples modified with nano $\mathrm{Al}_{2} \mathrm{O}_{3}$, (C) heat flow evaluation of the nano $\mathrm{SiO}_{2}$ modified cement paste, and (D) heat flow evaluation of the nano $\mathrm{Al}_{2} \mathrm{O}_{3}$ modified cement paste.

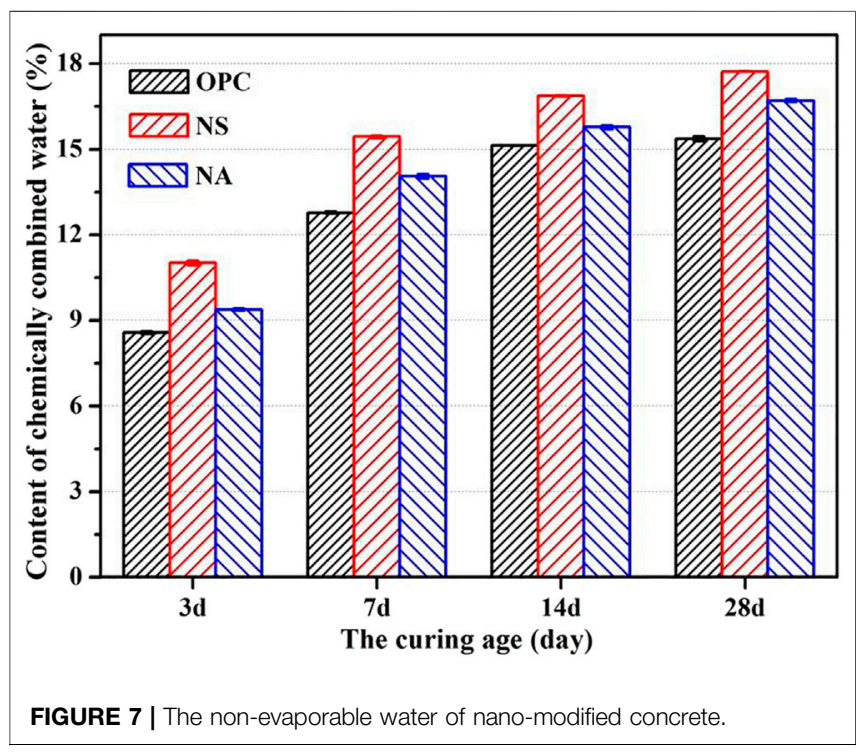

and results in the failure of concrete products (Farnam et al., 2015; Qiao et al., 2019).

Figures 8, 9 depict the fracture surface SEM morphologies and the corresponding EDS analysis of the control cement paste samples before and after $\mathrm{F} / \mathrm{T}$ along with $\mathrm{W} / \mathrm{D}$ cycles in a $3 \mathrm{wt} \%$ of $\mathrm{CaCl}_{2}$ solution. As can be seen from Figure 8, without the $\mathrm{F} / \mathrm{T}$ and $\mathrm{W} / \mathrm{D}$ cycles in the $\mathrm{CaCl}_{2}$ solution, the microstructure of the control paste sample is quite dense. The EDS result shows that the $\mathrm{Ca} / \mathrm{Si}$ ratio is about 2.5 , and no $\mathrm{Cl}$ can be detected. While after the F/T and W/D cycles in $\mathrm{CaCl}_{2}$ solution, the microstructure of the cement paste start to have continuous pores in the dense cementitious phase, and a colloidal precipitation layer was affiliated on the surface of the binder phase. The corresponding EDS results indicate that the $\mathrm{Ca}$ and $\mathrm{Cl}$ contents are slightly higher than the control sample, while the $\mathrm{Si}$ and $\mathrm{Fe}$ contents remain similar values.

Figures 10, 11 illustrate the SEM fracture surface microstructure and the corresponding EDS results of the 

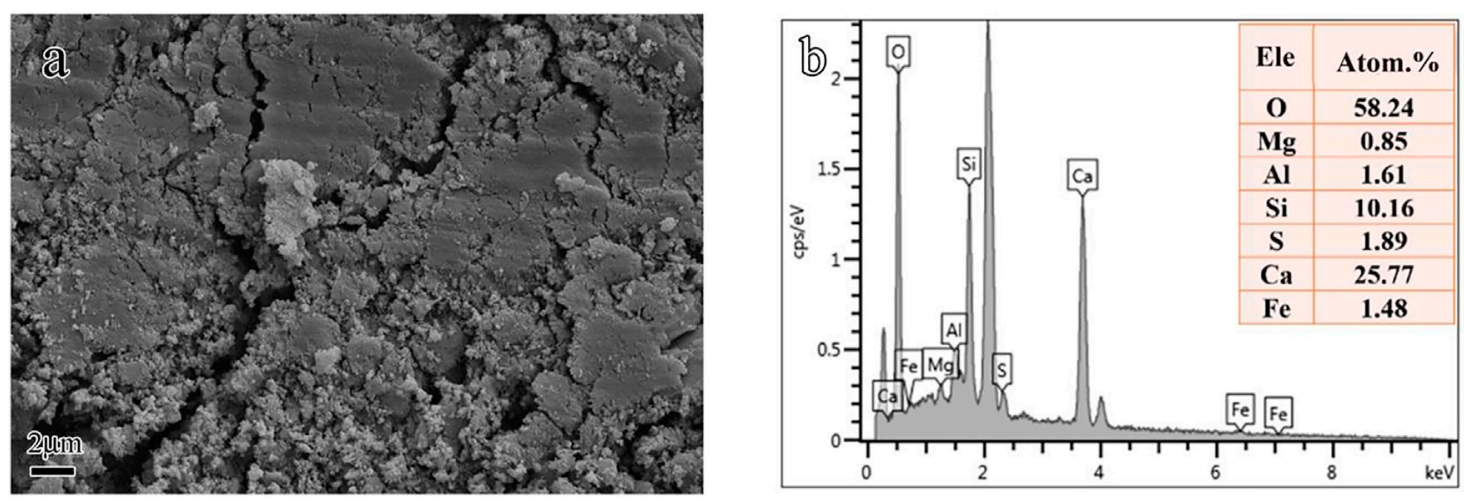

FIGURE 8 | SEM microstructure and the corresponding EDS results of the fracture surfaces of the cement paste in concrete without nano modification before F/T and W/D cycles.
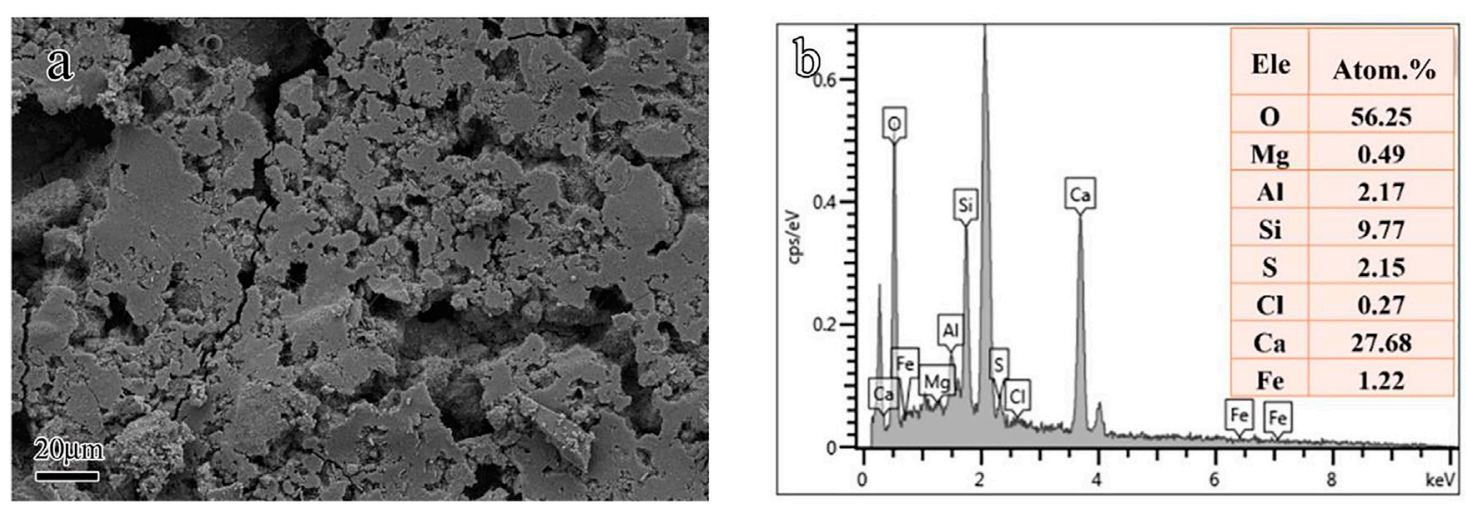

FIGURE 9 | SEM morphology and EDS results of the cement paste in concrete without nano modification after $\mathrm{F} / \mathrm{T}$ and $\mathrm{W} / \mathrm{D}$ cycles in 3 wt\% of CaCl ${ }_{2}$ solution.
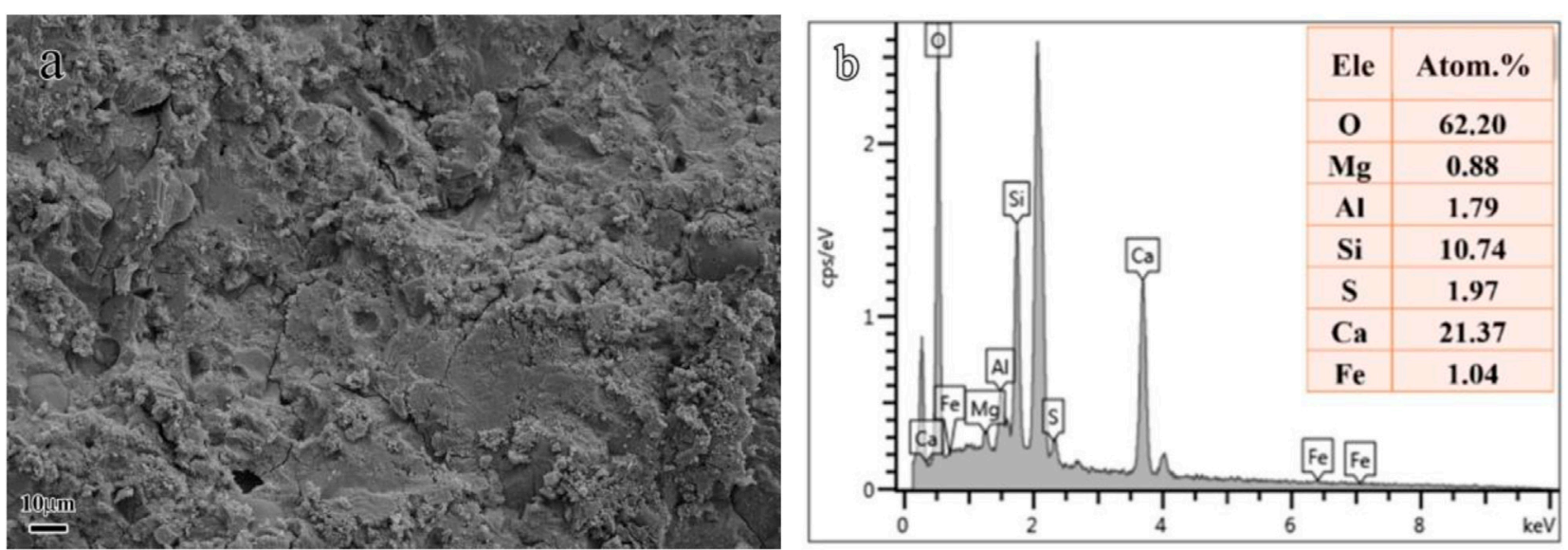

FIGURE 10 | SEM morphology and corresponding EDS results of the cement paste in concrete modified with nano $\mathrm{SiO}_{2}$ before $\mathrm{F} / \mathrm{T}$ and W/D cycles. 

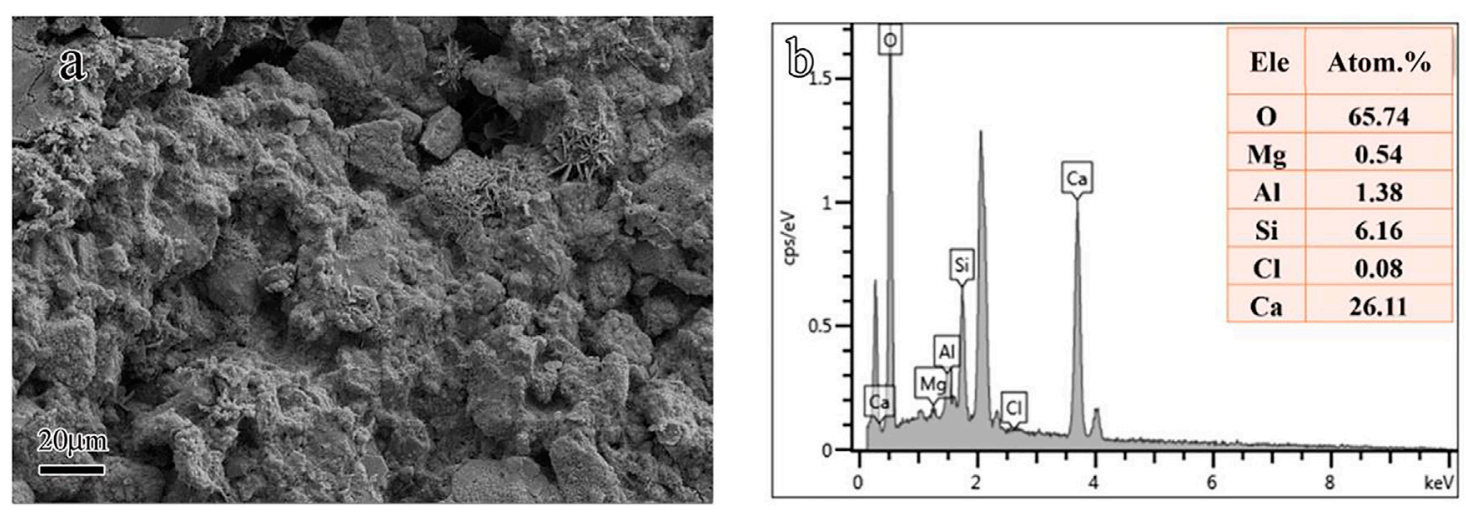

FIGURE 11 |SEM morphology and corresponding EDS results of the cement paste in concrete modified with nano $\mathrm{SiO}_{2}$ after $\mathrm{F} / \mathrm{T}$ and $\mathrm{W} / \mathrm{D}$ cycles in 3 wt $\%$ of $\mathrm{CaCl}_{2}$ solution.

cement paste samples modified with nano $\mathrm{SiO}_{2}$ before and after $\mathrm{F} / \mathrm{T}$ along with $\mathrm{W} / \mathrm{D}$ cycles in a $3 \mathrm{wt} \%$ of $\mathrm{CaCl}_{2}$ solution. As shown in Figure 10, before the F/T and W/D cycles in $\mathrm{CaCl}_{2}$ solution, coral shape hydration products can be observed, and the microstructure of the sample is quite dense. This is well agreed with the results from previous studies that the addition of nano $\mathrm{SiO}_{2}$ is beneficial to form high-density hydration products (Shah, 2013; Hou et al., 2013). The EDS result shows that the $\mathrm{Ca} / \mathrm{Si}$ ratio is about 2.0 , and a small amount of $\mathrm{S}$ can be detected. Similar to the

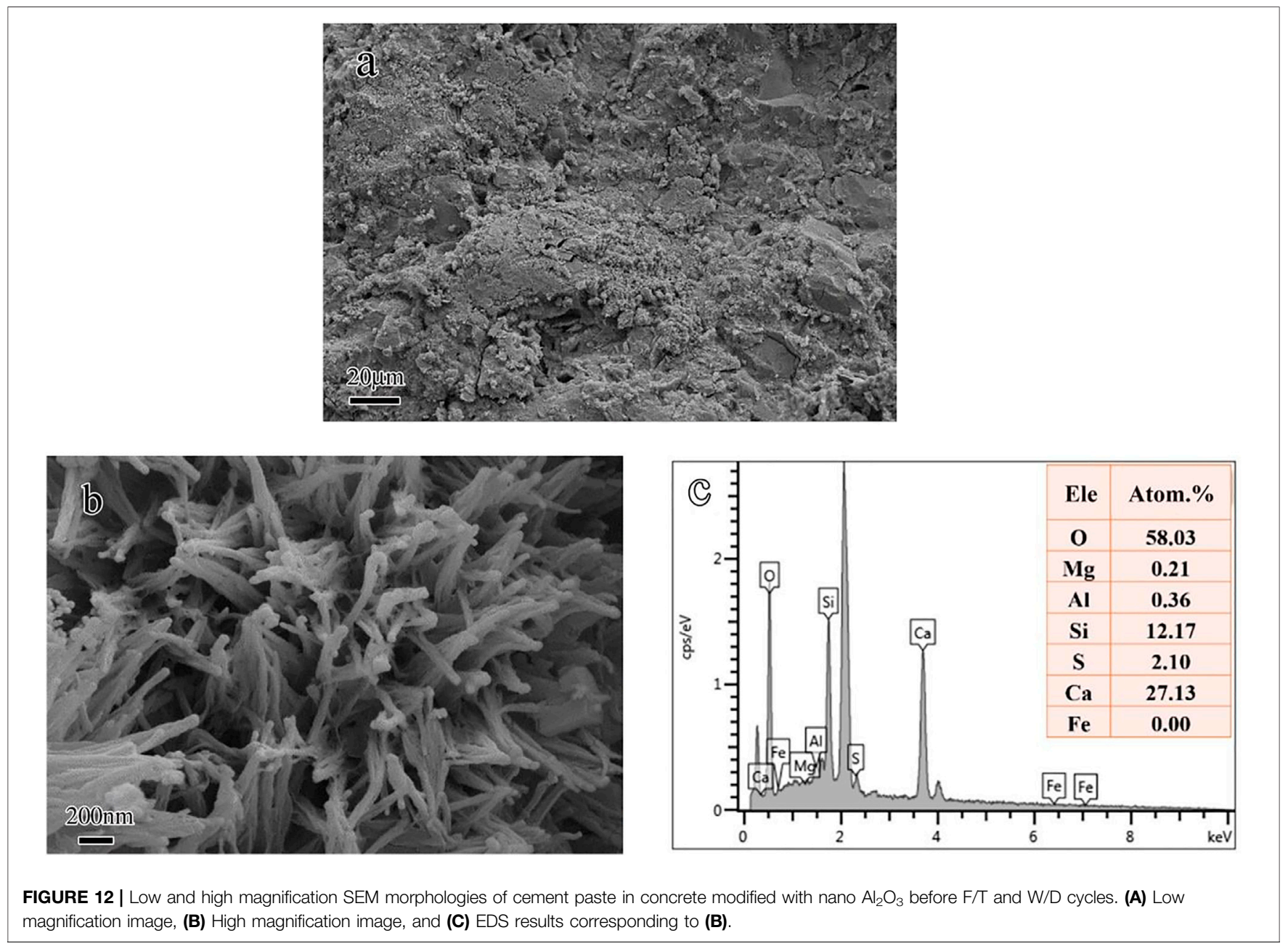



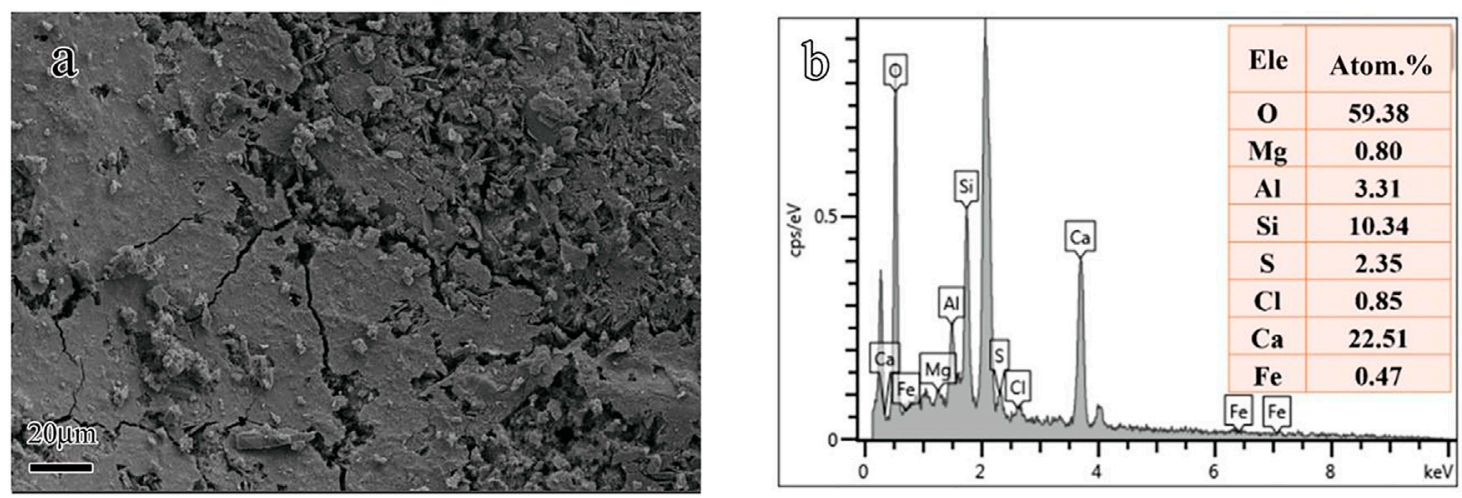

FIGURE 13 | (A) SEM morphology and (B) corresponding EDS results of the cement paste in concrete modified with nano $\mathrm{Al}_{2} \mathrm{O}_{3}$ after $\mathrm{F} / \mathrm{T}$ and $\mathrm{W} / \mathrm{D}$ cycles in 3 wt. $\%$ of $\mathrm{CaCl}_{2}$ solution.

microstructure of cement paste without nano modification, after the $\mathrm{F} / \mathrm{T}$ and $\mathrm{W} / \mathrm{D}$ cycles in $\mathrm{CaCl}_{2}$ solution, the dense structure of the binder phase has been broken, and a colloidal precipitation layer was affiliated on the surface of the binder phase. The corresponding EDS results indicate that the $\mathrm{Ca} / \mathrm{Si}$ ratio has changed to about 4.3 , and the $\mathrm{Cl}$ can be detected.

Figures 12, 13 demonstrate the microstructure and the corresponding EDS results of the nano $\mathrm{Al}_{2} \mathrm{O}_{3}$ modified cement paste before and after $\mathrm{F} / \mathrm{T}$ along with W/D cycles in a $3 \mathrm{wt} \%$ of $\mathrm{CaCl}_{2}$ solution. As can be seen from the low magnification fracture surface morphology (Figure 12A), without the $\mathrm{F} / \mathrm{T}$ and $\mathrm{W} / \mathrm{D}$ cycles in $\mathrm{CaCl}_{2}$ solution, the microstructure of the nano $\mathrm{Al}_{2} \mathrm{O}_{3}$ modified sample is also quite dense and no distinctive cracks or pores can be detected. Furthermore, it can be observed from the high magnification microstructure (Figure 12B), needle shape hydration products can be observed. The corresponding EDS result of this needle shape hydration product demonstrates that the $\mathrm{Ca} / \mathrm{Si}$ ratio of this phase is about 2.3, a small amount of $\mathrm{S}$, and no $\mathrm{Cl}$ can be detected. While after the $\mathrm{F} / \mathrm{T}$ and $\mathrm{W} / \mathrm{D}$ cycles in the $\mathrm{CaCl}_{2}$ solution, similar to previous ones, a large number of colloidal precipitates can be observed on the surface of the binder phase. The corresponding EDS results indicate that the $\mathrm{Ca} / \mathrm{Si}$ ratio has become 2.0, and the $\mathrm{Al}$ content is relatively higher than the other samples.

\section{CONCLUSION}

This work presents a comparative result to investigate the impacts of $\mathrm{CaCl}_{2}$ along with $\mathrm{F} / \mathrm{T}$ and $\mathrm{W} / \mathrm{D}$ cycles on the durability of concrete products modified with nano $\mathrm{SiO}_{2}$ and nano $\mathrm{Al}_{2} \mathrm{O}_{3}$. It was found that the environmental resistance of concrete materials can be remarkably enhanced with the addition of nanoparticles. The compressive and flexural strengths have increased about 15 and $13 \%$, respectively, corresponding to the dosage of $1.0 \mathrm{wt} \%$ of nano $\mathrm{SiO}_{2}$ and nano $\mathrm{Al}_{2} \mathrm{O}_{3}$. The electric flux has significantly decreased from 5,000 to $3,500^{\circ} \mathrm{C}$ and 4,100 , suggesting the reduction of the permeability. Besides, the heat of hydration testing results demonstrates that the nano $\mathrm{SiO}_{2}$ and nano $\mathrm{Al}_{2} \mathrm{O}_{3}$ have considerable impacts on accelerating the hydration process. The non-evaporable water contents have reduced with increasing contents of nano $\mathrm{SiO}_{2}$ and nano $\mathrm{Al}_{2} \mathrm{O}_{3}$. The SEM/EDS analysis demonstrates that the highdensity C-S-H phase will be formed. After the F/T and W/D cycles in a $\mathrm{CaCl}_{2}$ solution, although colloidal precipitates will be formed and the dense microstructure of the cement paste will be damaged, the addition of nanoparticles is beneficial to remain the dense structure of cement paste.

\section{DATA AVAILABILITY STATEMENT}

The original contributions presented in the study are included in the article/Supplementary Material, further inquiries can be directed to the corresponding authors.

\section{AUTHOR CONTRIBUTIONS}

YZ wrote most of this manuscript. YZ was in charge of implementing most of the materials manufacturing and properties testing. NX helped on the microstructure analysis, $\mathrm{PH}$ and LF helped the discussion and analyzing parts. NC and SZ organized the outline and the whole contents. All authors have read and agreed to the published version of the manuscript.

\section{FUNDING}

This research was funded by the National Key R\&D Program of China (2017YFB0310003), National Natural Science Foundation of China (Project Nos. 51772128 and 51632003), Youth Innovation Support Program of Shandong Colleges and Universities, Taishan Scholar Program, Case-by-Case Project for Top Outstanding Talents of Jinan, Double Hundred Foreign Expert Program (WST2018011), and Lianyungang 
Gaoxin District International Scientific Cooperation Program (HZ201902), Sino-European Research Center program (SERCM-20191201), and Lianyungang Haiyan Plan program (2019-

\section{REFERENCES}

Allen, A. J., and Thomas, J. J. (2007b). Analysis of C-S-H Gel and Cement Paste by Small-Angle Neutron Scattering. Cement Concrete Res. 37, 319-324. doi:10.1016/j.cemconres.2006.09.002

Allen, A. J., Thomas, J. J., and Jennings, H. M. (2007a). Composition and Density of Nanoscale Calcium-Silicate-Hydrate in Cement. Nat. Mater 6, 311-316. doi:10.1038/nmat1871

Behfarnia, K., and Salemi, N. (2013). The Effects of Nano-Silica and NanoAlumina on Frost Resistance of normal concrete. Construction Building Mater. 48, 580-584. doi:10.1016/j.conbuildmat.2013.07.088

Berra, M., Carassiti, F., Mangialardi, T., Paolini, A. E., and Sebastiani, M. (2012). Effects of Nanosilica Addition on Workability and Compressive Strength of Portland Cement Pastes. Construction Building Mater. 35, 666-675. doi:10.1016/j.conbuildmat.2012.04.132

Erdem, S., Hanbay, S., and Blankson, M. A. (2017). Self-sensing Damage Assessment and Image-Based Surface Crack Quantification of Carbon Nanofibre Reinforced concrete. Construction Building Mater. 134, 520-529. doi:10.1016/j.conbuildmat.2016.12.197

Fan, Y., Zhang, S., Wang, Q., and Shah, S. P. (2015). Effects of Nano-Kaolinite clay on the Freeze-Thaw Resistance of concrete. Cement and Concrete Composites 62, 1-12. doi:10.1016/j.cemconcomp.2015.05.001

Farnam, Y., Wiese, A., Bentz, D., Davis, J., and Weiss, J. (2015). Damage Development in Cementitious Materials Exposed to Magnesium Chloride Deicing Salt. Construction Building Mater. 93, 384-392. doi:10.1016/ j.conbuildmat.2015.06.004

Feng, D., Xie, N., Gong, C., Leng, Z., Xiao, H., Li, H., et al. (2013). Portland Cement Paste Modified by TiO2Nanoparticles: A Microstructure Perspective. Ind. Eng. Chem. Res. 52 (33), 11575-11582. doi:10.1021/ie4011595

Hakamy, A., Shaikh, F. U. A., and Low, I. M. (2014). Thermal and Mechanical Properties of Hemp Fabric-Reinforced Nanoclay-Cement nanocompositesThermal and Mechanical Properties of Hemp FabricReinforced Nanoclay-Cement Nanocomposites. J. Mater. Sci. 49 (4), 1684-1694. doi:10.1007/s10853-013-7853-0

Heikal, M. (2016). Characteristics, Textural Properties and Fire Resistance of Cement Pastes Containing Fe2O3 Nano-Particles. J. Therm. Anal. Calorim. 126 (3), 1077-1087. doi:10.1007/s10973-016-5715-0

Hou, P., Kawashima, S., Kong, D., CorrCorr, D. J., Qian, J., and Shah, S. P. (2013). Modification Effects of Colloidal nanoSiO2 on Cement Hydration and its Gel Property. Composites B: Eng. 45 (1), 440-448. doi:10.1016/ j.compositesb.2012.05.056

Kong, D., Du, X., Wei, S., Zhang, H., Yang, Y., and Shah, S. P. (2012). Influence of Nano-Silica Agglomeration on Microstructure and Properties of the Hardened Cement-Based Materials. Construction Building Mater. 37, 707-715. doi:10.1016/j.conbuildmat.2012.08.006

Kong, D., Su, Y., Du, X., Yang, Y., Wei, S., and Shah, S. P. (2013). Influence of Nano-Silica Agglomeration on Fresh Properties of Cement Pastes. Construction Building Mater. 43, 557-562. doi:10.1016/j.conbuildmat.2013.02.066

León, N., Massana, J., Alonso, F., Moragues, A., and Sánchez-Espinosa, E. (2014). Effect of Nano-Si2O and Nano-Al2O3 on Cement Mortars for Use in Agriculture and Livestock Production. Biosyst. Eng. 123, 1-11. doi:10.1016/ j.biosystemseng.2014.04.009

Li, H., Xiao, H.-g., Yuan, J., and Ou, J. (2004). Microstructure of Cement Mortar with Nano-Particles. Composites Part B: Eng. 35 (2), 185-189. doi:10.1016/ s1359-8368(03)00052-0

Li, H., Zhang, M.-h., and Ou, J.-p. (2006). Abrasion Resistance of concrete Containing Nano-Particles for Pavement. Wear 260, 1262-1266. doi:10.1016/j.wear.2005.08.006

Lim, S., and Mondal, P. (2014). Micro- and Nano-Scale Characterization to Study the thermal Degradation of Cement-Based Materials. Mater. Characterization 92, 15-25. doi:10.1016/j.matchar.2014.02.010
QD-002). Some or all data, models, or code that support the findings of this study are available from the corresponding author upon reasonable request.

Lu, S-N., Xie, N., Feng, L-C., and Zhong, J. (2015). Applications of Nanostructured Carbon Materials in Constructions: The State of the Art. J. Nanomater. 2015, 6.

Luo, J., Hou, D., Li, Q., Wu, C., and Zhang, C. (2017). Comprehensive Performances of Carbon Nanotube Reinforced Foam concrete with Tetraethyl Orthosilicate Impregnation. Construction Building Mater. 131, 512-516. doi:10.1016/j.conbuildmat.2016.11.105

Lv, S., Ma, Y., Qiu, C., Sun, T., Liu, J., and Zhou, Q. (2013). Effect of Graphene Oxide Nanosheets of Microstructure and Mechanical Properties of Cement Composites. Construction building Mater. 49, 121-127. doi:10.1016/ j.conbuildmat.2013.08.022

Meng, T., Yu, Y., Qian, X., Zhan, S., and Qian, K. (2012). Effect of Nano-TiO2 on the Mechanical Properties of Cement Mortar. Construction Building Mater. 29, 241-245. doi:10.1016/j.conbuildmat.2011.10.047

Monteiro, P. J. M., Kirchheim, A. P., Chae, S., Fischer, P., MacDowell, A. A., Schaible, E., et al. (2009). Characterizing the Nano and Micro Structure of concrete to Improve its Durability. Cement and Concrete Composites 31, 577-584. doi:10.1016/j.cemconcomp.2008.12.007

Morsy, M. S., Al-Salloum, Y. A., Abbas, H., and Alsayed, S. H. (2012). Behavior of Blended Cement Mortars Containing Nano-Metakaolin at Elevated Temperatures. Construction Building Mater. 35, 900-905. doi:10.1016/ j.conbuildmat.2012.04.099

Morsy, M. S., Alsayed, S. H., and Aqel, M. (2011). Hybrid Effect of Carbon Nanotube and Nano-clay on Physico-Mechanical Properties of Cement Mortar. Construction Building Mater. 25 (1), 145-149. doi:10.1016/ j.conbuildmat.2010.06.046

Nazari, A., Riahi, S., Riahi, S., Shamekhi, S. F., and Khademno, A. (2010). Influence of Al2O3 Nanoparticles on the Compressive Strength and Workability of Blended concrete. J. Am. Sci. 6, 6-9.

Pan, Z., He, L., Qiu, L., Korayem, A. H., Li, G., Zhu, J. W., et al. (2015). Mechanical Properties and Microstructure of a Graphene Oxide-Cement Composite. Cement and Concrete Composites 58, 140-147. doi:10.1016/ j.cemconcomp.2015.02.001

Peterson, K., Julio-Betancourt, G., Sutter, L., Hooton, R. D., and Johnston, D. (2013). Observations of Chloride Ingress and Calcium Oxychloride Formation in Laboratory concrete and Mortar at $5^{\circ} \mathrm{C}$. Cement Concrete Res. 45, 79-90. doi:10.1016/j.cemconres.2013.01.001

Qiao, C., Suraneni, P., Nathalene Wei Ying, T., Choudhary, A., and Weiss, J. (2019). Chloride Binding of Cement Pastes with Fly Ash Exposed to $\mathrm{CaCl} 2$ Solutions at 5 and $23{ }^{\circ} \mathrm{C}$. Cement and Concrete Composites 97, 43-53. doi:10.1016/j.cemconcomp.2018.12.011

Qiao, C., Suraneni, P., and Weiss, J. (2018a). Flexural Strength Reduction of Cement Pastes Exposed to $\mathrm{CaCl} 2$ Solutions. Cement and Concrete Composites 86, 297-305. doi:10.1016/j.cemconcomp.2017.11.021

Qiao, C., Suraneni, P., and Weiss, J. (2018b). Flexural Strength Reduction of Cement Pastes Exposed to $\mathrm{CaCl} 2$ Solutions. Cement and Concrete Composites 86, 297-305. doi:10.1016/j.cemconcomp.2017.11.021

Qing, Y., Zenan, Z., Deyu, K., and Rongshen, C. (2007). Influence of Nano-SiO2 Addition on Properties of Hardened Cement Paste as Compared with Silica Fume. Construction Building Mater. 21 (3), 539-545. doi:10.1016/ j.conbuildmat.2005.09.001

Salemi, N., and Behfarnia, K. (2013). Effect of Nano-Particles on Durability of Fiber-Reinforced concrete Pavement. Construction Building Mater. 48, 934-941. doi:10.1016/j.conbuildmat.2013.07.037

Shi, X., Veneziano, D., Xie, N., and Gong, J. (2013). Use of Chloride-Based Ice Control Products for Sustainable winter Maintenance: A Balanced Perspective. Cold Regions Sci. Technology 86, 104-112. doi:10.1016/j.coldregions.2012.11.001

Shiho, K., Hou, P., David, J., and Shah, S. P. (2013). Modification of Cement-Based Materials with Nanoparticles. Cement and Concrete Composites 36, 8-15. doi:10.1016/j.cemconcomp.2012.06.012

Singh, L. P., Karade, S. R., Bhattacharyya, S. K., Yousuf, M. M., and Ahalawat, S. (2013). Beneficial Role of Nanosilica in Cement Based Materials - A Review. Construction Building Mater. 47, 1069-1077. doi:10.1016/j.conbuildmat.2013.05.052 
Xie, N., Dang, Y., and Shi, X. (2019). New Insights into How $\mathrm{MgCl} 2$ Deteriorates Portland Cement concrete. Cement Concrete Res. 120, 244-255. doi:10.1016/ j.cemconres.2019.03.026

Xie, N., Shi, X., and Zhang, Y. (2017). Impacts of Potassium Acetate and SodiumChloride Deicers on concrete. J. Mater. Civil Eng. 29, 04016229. doi:10.1061/ (asce)mt.1943-5533.0001754

Xu, Z., and Viehland, D. (1996). Observation of a Mesostructure in Calcium Silicate Hydrate Gels of Portland Cement. Phys. Rev. Lett. 77, 952-955. doi:10.1103/ physrevlett.77.952

Zhang, R., Cheng, X., Hou, P., and Ye, Z. (2015). Influences of Nano-TiO2 on the Properties of Cement-Based Materials: Hydration and Drying Shrinkage. Construction Building Mater. 81, 35-41. doi:10.1016/j.conbuildmat.2015.02.003

Zhou, Z., Xie, N., Cheng, X., Feng, L., Hou, P., Huang, S., et al. (2020). Electrical Properties of Low Dosage Carbon Nanofiber/cement Composite: Percolation
Behavior and Polarization Effect. Cement and Concrete Composites 109, 103539. doi:10.1016/j.cemconcomp.2020.103539

Conflict of Interest: The authors declare that the research was conducted in the absence of any commercial or financial relationships that could be construed as a potential conflict of interest.

Copyright (c) 2021 Zhao, Cui, Zhao, Zhu, Hou, Feng and Xie. This is an open-access article distributed under the terms of the Creative Commons Attribution License (CC $B Y)$. The use, distribution or reproduction in other forums is permitted, provided the original author(s) and the copyright owner(s) are credited and that the original publication in this journal is cited, in accordance with accepted academic practice. No use, distribution or reproduction is permitted which does not comply with these terms. 